\title{
Effects of Bambusa tulda on the proliferation of human stem cells
}

\author{
HYUNJIN LEE ${ }^{1}$, MOHAMMAD SALAH UDDIN ${ }^{2}$, SANG WOO LEE $^{3}$, SANGHO CHOI $^{3}$ and JUN-BEOM PARK ${ }^{1}$ \\ ${ }^{1}$ Department of Periodontics, College of Medicine, The Catholic University of Korea, Seoul 06591, Republic of Korea; \\ ${ }^{2}$ Ethnobotanical Database of Bangladesh, Dhaka 1208, People's Republic of Bangladesh ; ${ }^{3}$ International Biological Material \\ Research Center, Korea Research Institute of Bioscience and Biotechnology, Daejeon 34141, Republic of Korea
}

Received April 8,2017; Accepted July 27, 2017

DOI: $10.3892 /$ etm.2017.5276

\begin{abstract}
To date, the effects of Bambusa tulda on stem cells have not been thoroughly assessed. The present study aimed to evaluate the effects of Bambusa tulda extract on the morphology and proliferative potential of human mesenchymal stem cells derived from the gingiva. The stem cells were cultured in a growth medium in the presence of Bambusa tulda methanolic extract (BBT) at concentrations ranging from 0.001 to $1 \%$. Evaluation of cell morphology and cellular proliferation as well as immunofluorescent assays for collagen I were performed on days 1, 3, 5 and 7. Stem cells in the control group displayed a fibroblast-like morphology, and BBT treatment did not produce any noticeable morphological changes. However, application of $1 \%$ BBT produced a significant increase in cell proliferation. BBT, particularly at the concentration of $1 \%$, also caused a noticeable increase of collagen I expression at day 1 and day 3. Based on these findings, it was concluded that BBT exerted beneficial effects on the proliferation of mesenchymal stem cells and enhanced collagen I expression at early time points.
\end{abstract}

\section{Introduction}

Bambusa tulda Roxburgh, also known as Indian timber bamboo, is an evergreen gregarious bamboo with grey or greyish-green culms that is native to the Indian subcontinent, Indochina, Tibet and Yunnan, and naturalized in Puerto Rico and parts of South America (1). Bambusa tulda has been used for various purposes and has been widely considered as one of the most useful bamboo species (2). Bambusa tulda is widely used in paper pulp industry in Asia (3). Bambusa tulda

Correspondence to: Dr Jun-Beom Park, Department of Periodontics, College of Medicine, The Catholic University of Korea, 222 Banpo-daero, Seocho-gu, Seoul 06591, Republic of Korea

E-mail: jbassoonis@yahoo.co.kr

Key words: Bambusa, cell proliferation, cell survival, herbal medicine, medicinal plants, stem cells produces nutritive shoots and there is high demand for edible bamboo shoots in many Asian ethnic groups (4).

The leaves of Bambusa tulda are 3-4 $\mathrm{cm}$ broad and 20-35 cm in length with an oblong-lanceolate shape (5). Medicinal uses of the leaves of Bambusa tulda have not yet been widely studied, and the effects of Bambusa tulda leaf extract on stem cells remain to be thoroughly assessed. The present study aimed to evaluate the effects of Bambusa tulda methanolic extract (BBT) on the morphology and proliferative potential of human mesenchymal stem cells.

\section{Materials and methods}

Preparation of plant materials. The Bambusa tulda Roxburgh was collected in the village of Amki, Sonaimuri Upazilla, Noakhali District, Bangladesh and a voucher specimen (no. PB022073) was deposited in the herbarium of the Korea Research Institute of Bioscience and Biotechnology. After drying and grinding the leaves of Bambusa tulda, the powder $(63 \mathrm{~g})$ was added to $500 \mathrm{ml}$ methanol. The extraction was performed using the method of repercolation at room temperature. The extract was filtered and concentrated by a rotavapor under reduced pressure to obtain $2.75 \mathrm{~g}$ BBT.

Stem cells isolated from human gingiva. A healthy, 63-year-old, female patient visiting the Department of Periodontics of Seoul St. Mary's Hospital (College of Medicine, the Catholic University of Korea, Seoul, Korea) provided the gingivae for the study. The Institutional Review Board at Seoul St. Mary's Hospital reviewed and gave approval for the study (no. KC11SISI0348), and written informed consent was obtained from the patient. All the methods used in this study were performed in accordance with the ethical standards of the Institutional Research Committee and with the 1964 Helsinki Declaration and its later amendments. The epithelium of the obtained gingiva was removed and the tissue was cut into 1-2 mm fragments. The gingival tissues were digested with media containing dispase $(1 \mathrm{mg} / \mathrm{ml}$; Sigma-Aldrich; Merck KGaA, Darmstadt, Germany) and collagenase IV (2 mg/ml; Sigma-Aldrich; Merck KGaA) (6). Cells that were not attached to the culture dish were removed. The media was changed every 2-3 days and cells were cultured in an incubator with a humidified atmosphere of $5 \% \mathrm{CO}_{2}$ and $95 \%$ air at $37^{\circ} \mathrm{C}$. 

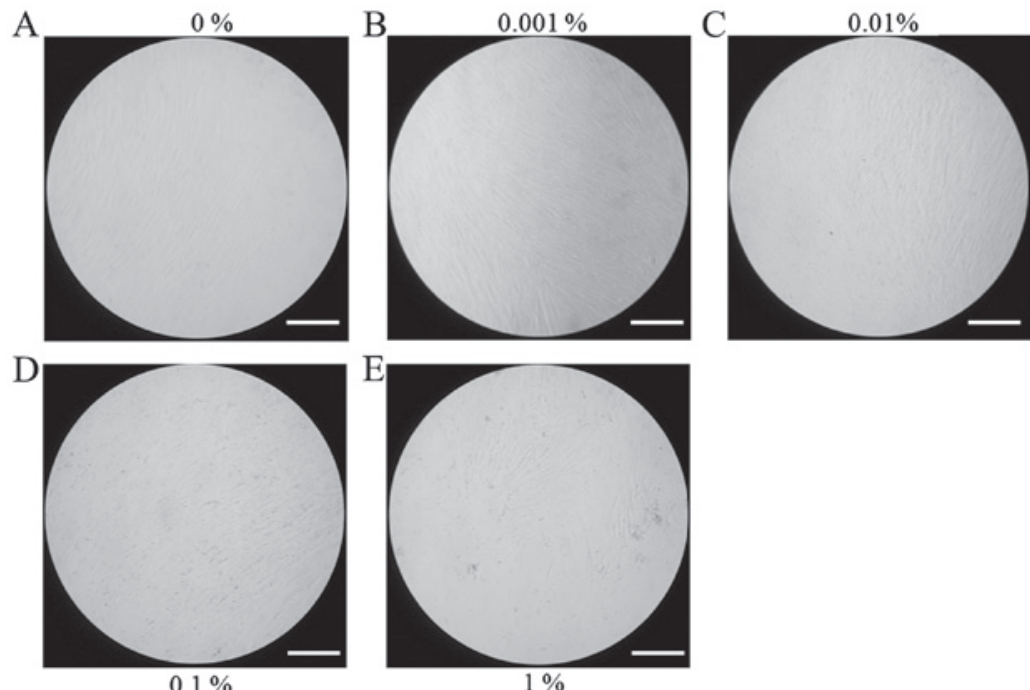

Figure 1. Evaluation of cell morphology on day 1 using inverted microscopy following addition of different concentrations of BBT to the growth media. (A) Control group and (B) 0.001, (C) 0.01, (D) 0.1 and (E) 1\% BBT groups (original magnification, x200; scale bar, $200 \mu \mathrm{m}$ ). BBT, Bambusa tulda methanolic extract.

Evaluation of cellular morphology. The cells were seeded in 96-well plates at a density of $2.0 \times 10^{3}$ cells/well and incubated in control medium $[\alpha$-minimal essential medium $(\alpha$-MEM); Gibco; Thermo Fisher Scientific, Inc., Waltham, MA, USA] supplemented with $15 \%$ fetal bovine serum (FBS; Gibco; Thermo Fisher Scientific, Inc.), 200 mM L-glutamine, $10 \mathrm{mM}$ ascorbic acid 2-phosphate, $100 \mathrm{U} / \mathrm{ml}$ penicillin and $100 \mu \mathrm{g} / \mathrm{ml}$ streptomycin (all from Sigma-Aldrich; Merck KGaA) in the presence of BBT at final concentrations of 0 (control), 0.001, $0.01,0.1$ and $1 \%$. BBT was dissolved in dimethyl sulfoxide (DMSO) and equal amounts of DMSO $(0.1 \%)$ were added to each culture sample to offset the influence of this dissolving vehicle. The morphology of the stem cells was evaluated using an inverted microscope (CKX41SF; Olympus Corp., Tokyo, Japan) on days 1, 3, 5 and 7 .

Cellular proliferation. Evaluation of the proliferation of the cells grown in medium containing BBT was performed on days 1, 3, 5 and 7 using the Cell Counting Kit-8 (CCK-8; Dojindo, Tokyo, Japan) assay. Tetrazolium monosodium salt was added to the culture, followed by incubation at $37^{\circ} \mathrm{C}$ for $2 \mathrm{~h}$. The spectrophotometric absorbance at $450 \mathrm{~nm}$ was determined using a microplate reader (BioTek Instruments Inc., Winooski, VT, USA).

Immunofluorescence. Collagen I antibody (cat. no. ab76956; Abcam, Cambridge, UK) was used for the immunofluorescent assay performed on days 1,3,5 and 7. Following the specific incubation with BBT, the cells were fixed, permeabilized, blocked and incubated with primary antibodies to collagen I (1:67) overnight at $4^{\circ} \mathrm{C}$. The cultures were incubated for two h at room temperature with fluorescein isothiocyanate-conjugated secondary antibody (cat. no. F2761; 1:100; Thermo Fisher Scientific, Inc.) and then stained with DAPI. A fluorescence microscope (Axiovert 200; Zeiss, Jena, Germany) was used for the analyses.

Statistical analysis. Values are expressed as the mean \pm standard deviation of the experiments. A test of normality was performed and one-way analysis of variance with Scheffe's test post hoc test was performed to determine differences between the groups with commercially available software (SPSS 12 for Windows; SPSS Inc., Chicago, IL, USA). $\mathrm{P}<0.05$ was considered to indicate a statistically significant difference.

\section{Results}

Evaluation of cell morphology. The morphology of stem cells treated with BBT at final concentrations of $0,0.001,0.01,0.1$ and $1 \%$ on day 1 is presented in Fig. 1 . Stem cells in the control group had a fibroblast-like morphology on day 1 (Fig. 1A). No noticeable differences in the morphology of stem cells treated with BBT were observed when compared with that in the untreated control group (Fig. 1B-E). The results on the cell morphology at days 3, 5 and 7 are presented in Figs. 2-4, respectively. Cells appeared to be more densely gathered in the $1 \%$ group at day 5 and 7 compared with other groups at the same time points.

Cellular proliferation. The results of the CCK-8 assay revealing the effects of BBT on cellular viability on days 1,3,5 and 7 are presented in Fig. 5. After 1 day of culture, the number of viable cells in the $0.001,0.01,0.1$ and $1 \%$ BBT groups was $112.5 \pm 17.5$, $121.2 \pm 14.3,126.9 \pm 10.5$ and $157.0 \pm 13.1 \%$ of that of the control group, respectively $(\mathrm{P}<0.05)$. On day 3 , the relative number of viable cells in the $0.001,0.01,0.1$ and $1 \%$ BBT groups was $103.4 \pm 12.5,116.7 \pm 15.1,121.6 \pm 4.2$ and $184.4 \pm 13.3 \%$, respectively, of that in the control group $(\mathrm{P}<0.05)$. The relative number of viable cells in the $0.001,0.01,0.1$ and $1 \%$ groups on day 5 was $110.4 \pm 10.6,113.4 \pm 14.8,102.6 \pm 5.2$ and $136.4 \pm 7.7 \%$ of the control group, respectively $(\mathrm{P}<0.05)$. On day 7 , the relative number of viable cells in the $0.001,0.01,0.1$ and $1 \%$ groups was $79.8 \pm 3.7,75.0 \pm 2.4,76.8 \pm 4.3$ and $70.9 \pm 1.6 \%$, respectively, compared with that in the control group.

Immunofluorescence. Representative immunofluorescence images for collagen I staining on days 1, 3, 5 and 7 for 

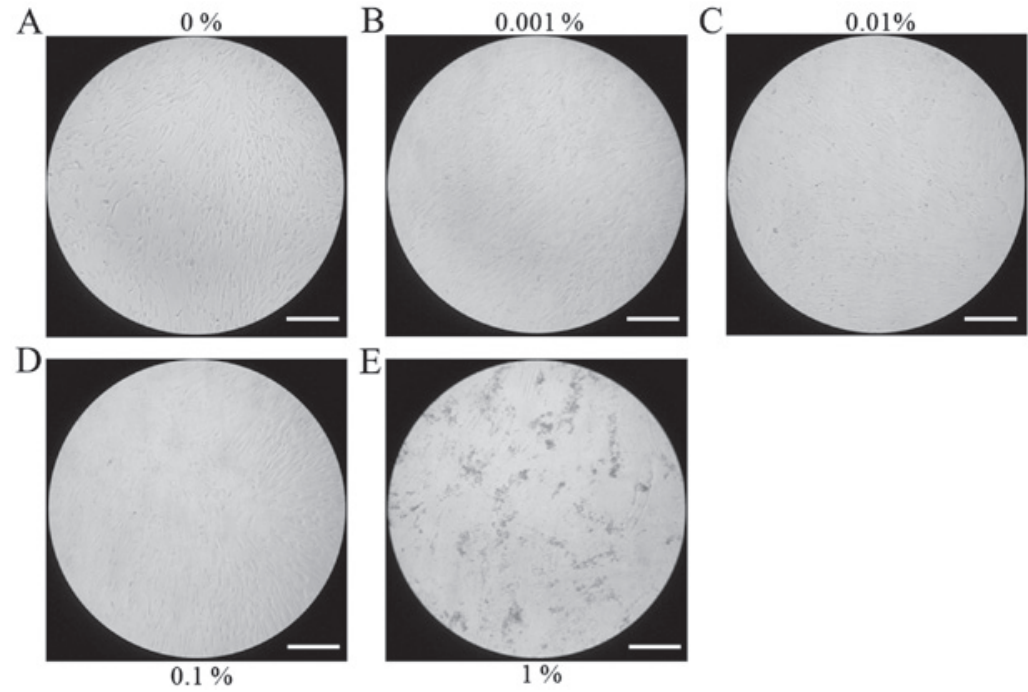

Figure 2. Evaluation of cell morphology on day 3 following addition of different concentrations of BBT to the growth media. (A) Control group and (B) 0.001 , (C) 0.01 , (D) 0.1 and (E) $1 \%$ BBT groups (original magnification, x200; scale bar, $200 \mu \mathrm{m}$ ). BBT, Bambusa tulda methanolic extract.
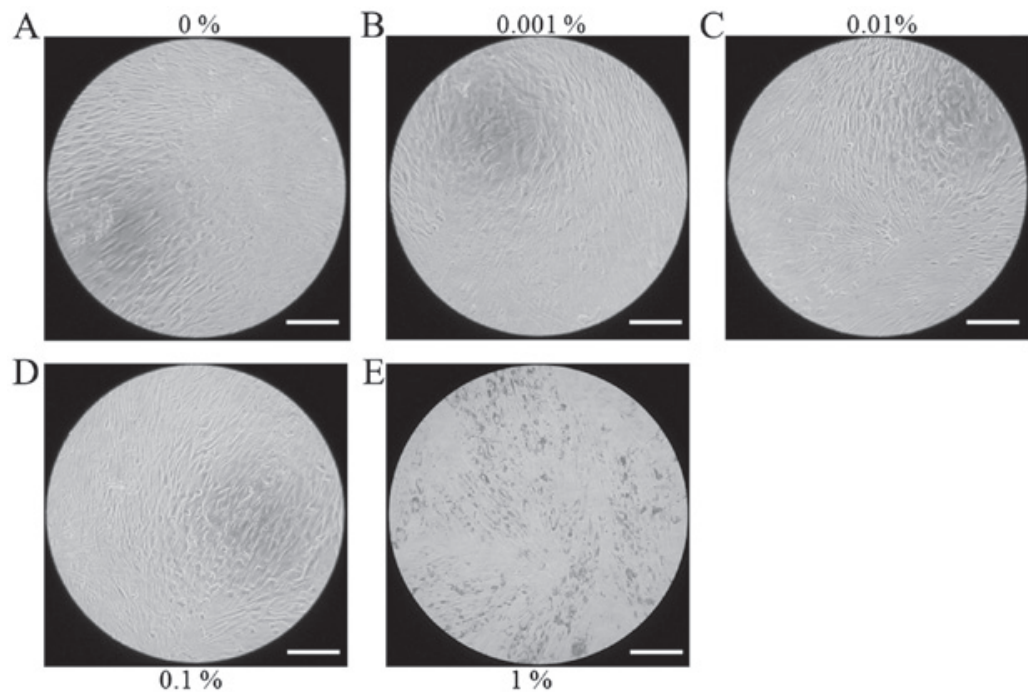

Figure 3. Evaluation of cell morphology on day 5 following addition of different concentrations of BBT to the growth media. (A) Control group and (B) 0.001 , (C) 0.01 , (D) 0.1 and (E) $1 \%$ BBT groups (original magnification, x200; scale bar, $200 \mu \mathrm{m}$ ). BBT, Bambusa tulda methanolic extract.
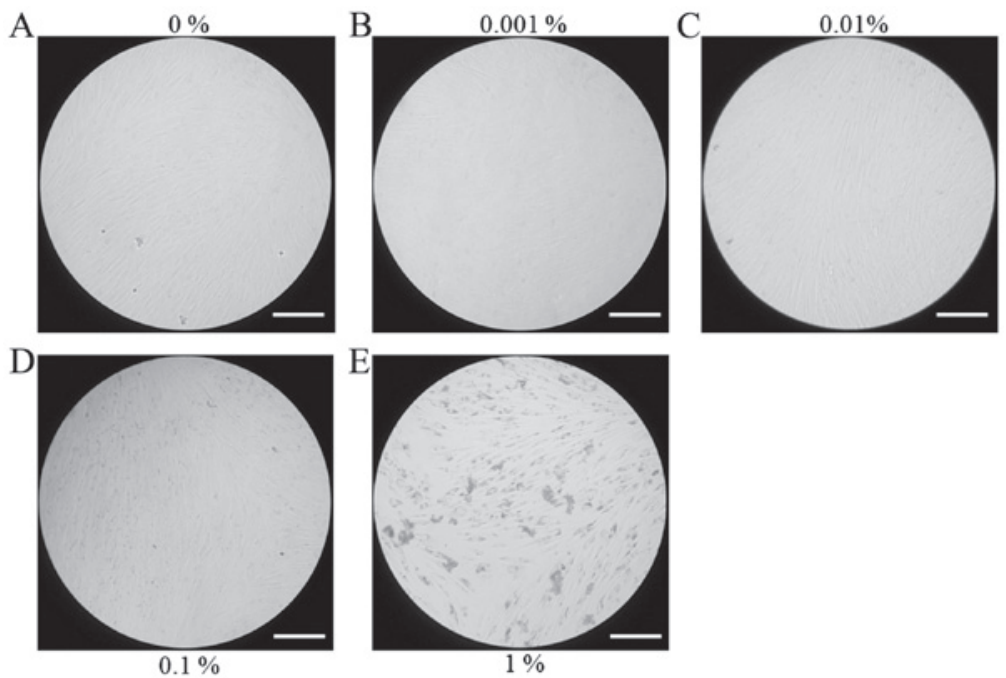

Figure 4. Evaluation of cell morphology on day 7 following addition of different concentrations of BBT to the growth media. (A) Control group and (B) 0.001 , (C) 0.01 , (D) 0.1 and (E) $1 \%$ BBT groups (original magnification, x200; scale bar, $200 \mu \mathrm{m}$ ). BBT, Bambusa tulda methanolic extract. 

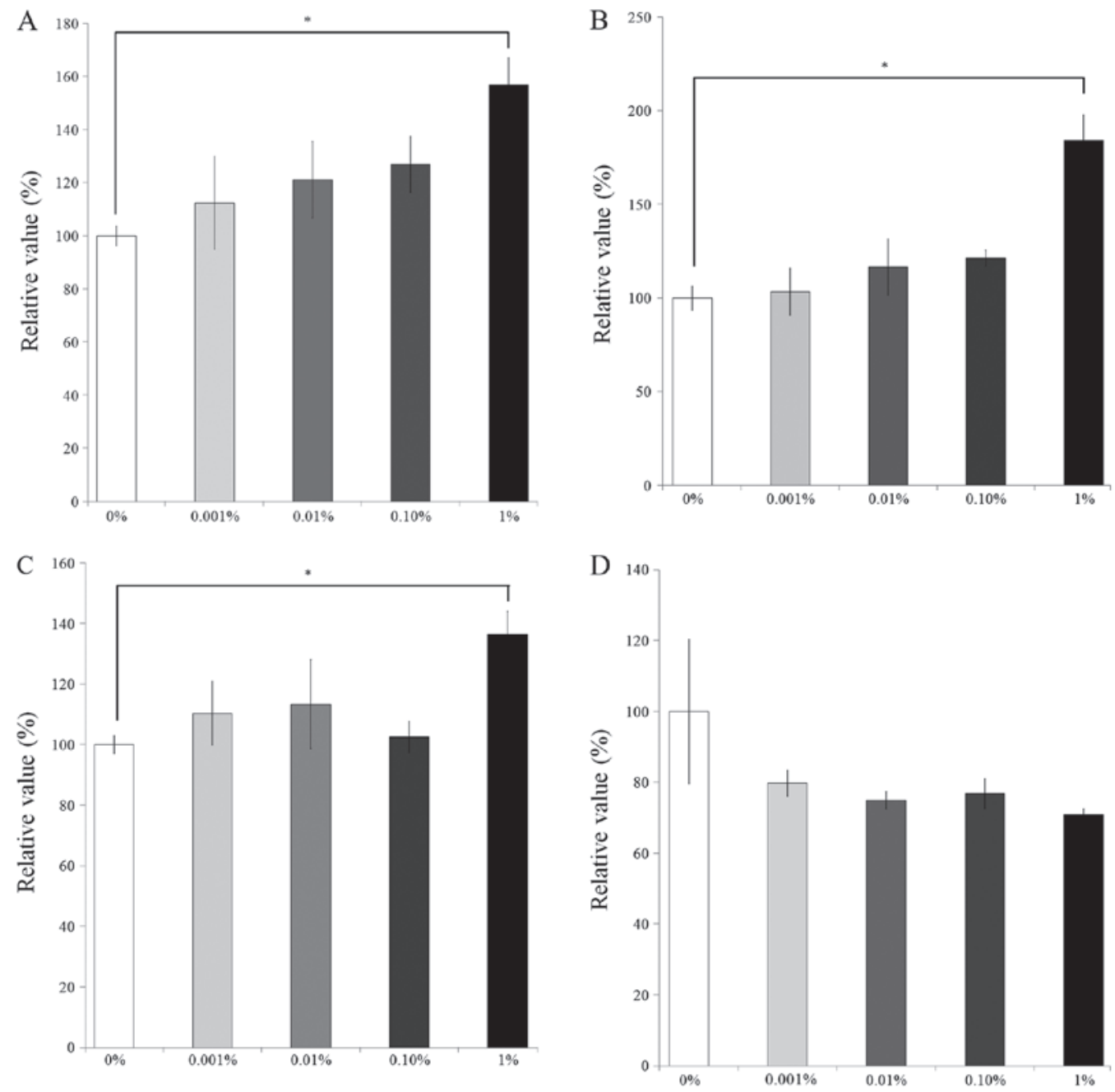

Figure 5. The Cell Counting Kit-8 assay results for stem cells cultured with various concentrations of Bambusa tulda methanolic extract for (A) 1, (B) 3, (C) 5 and (D) 7 days. ${ }^{*} \mathrm{P}<0.05$ vs. untreated control.

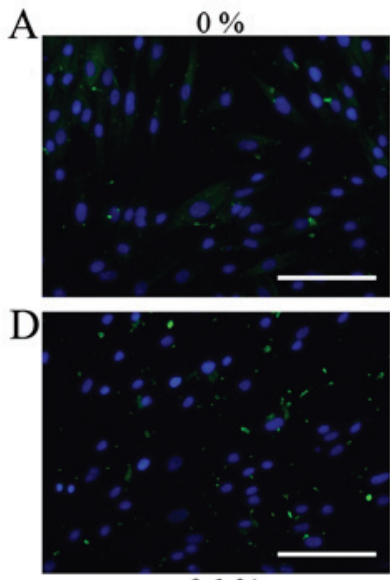

$0.1 \%$
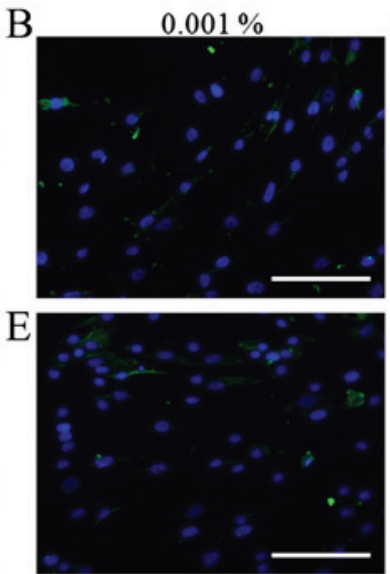

$1 \%$

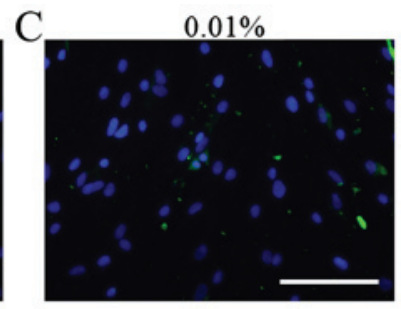

Figure 6. Immunofluorescence staining for collagen I after 1 day of incubation with BBT. (A) Control group and (B) 0.001 , (C) 0.01 , (D) 0.1 and (E) $1 \%$ BBT groups (original magnification, x200; scale bar, $200 \mu \mathrm{m}$ ). BBT, Bambusa tulda methanolic extract.

the cells treated with various concentrations of BBT are presented in Figs. 6-9. No marked changes in the expression of collagen I were observed on day 1 (Fig. 6). On day 3, a noticeable increase of collagen I expression was observed following the application of BBT, particularly at a concentration of $1 \%$ (Fig. 7). However, the results on day 5 indicated 


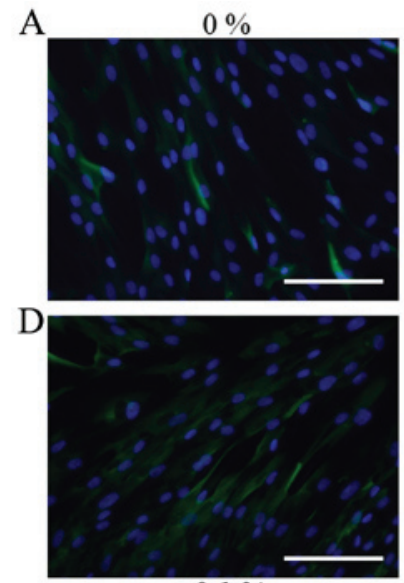

$0.1 \%$
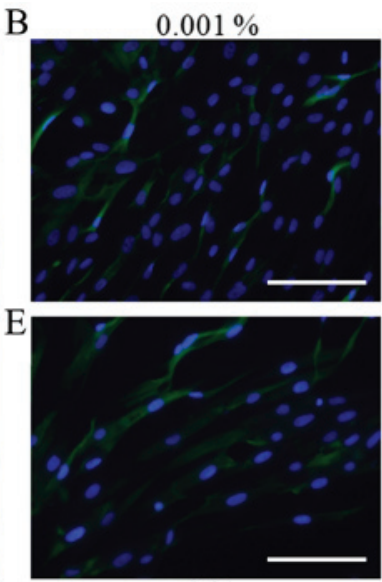

$1 \%$

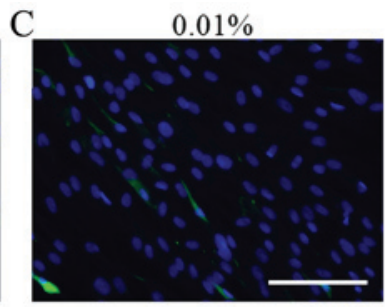

Figure 7. Immunofluorescence staining for collagen I after 3 days of incubation with BBT. (A) Control group and (B) 0.001 , (C) 0.01 , (D) 0.1 and (E) $1 \%$ BBT groups (original magnification, x200; scale bar, $200 \mu \mathrm{m}$ ). BBT, Bambusa tulda methanolic extract.

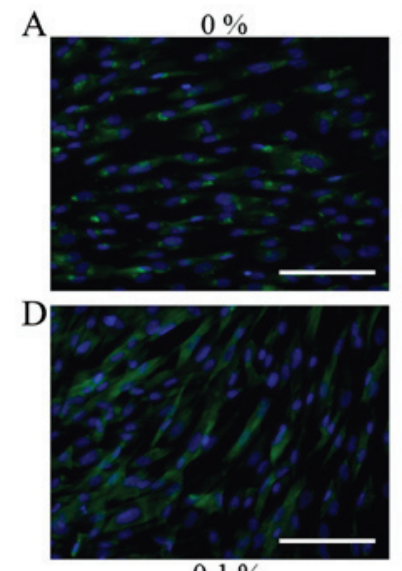

$0.1 \%$
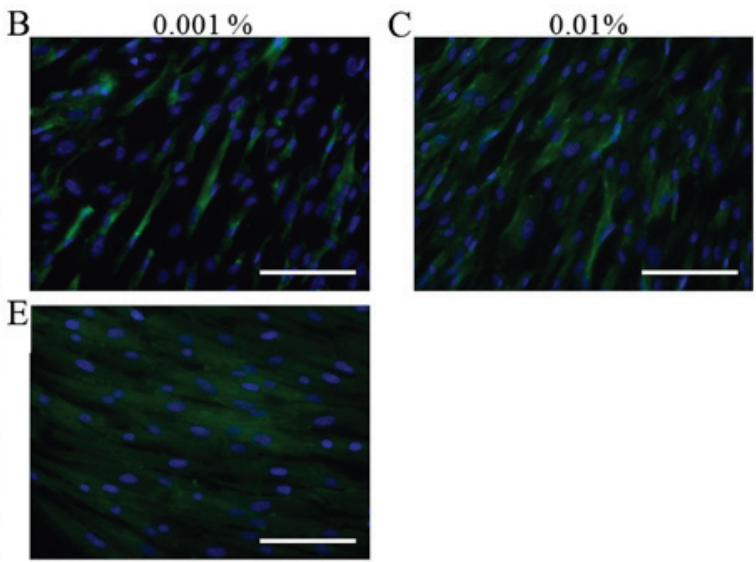

$1 \%$

Figure 8. Immunofluorescence staining for collagen I after 5 days of incubation with BBT. (A) Control group and (B) 0.001 , (C) 0.01 , (D) 0.1 and (E) $1 \%$ BBT groups (original magnification, x200; scale bar, $200 \mu \mathrm{m}$ ). BBT, Bambusa tulda methanolic extract.

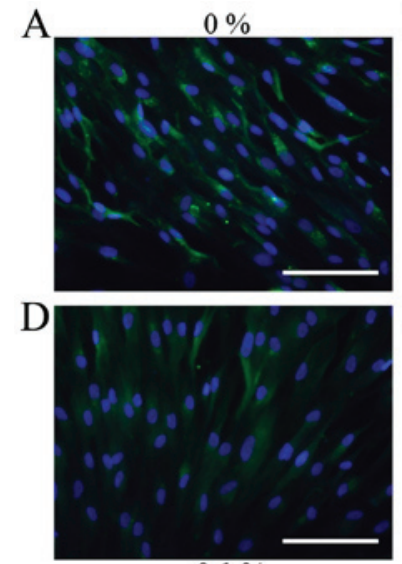

$0.1 \%$
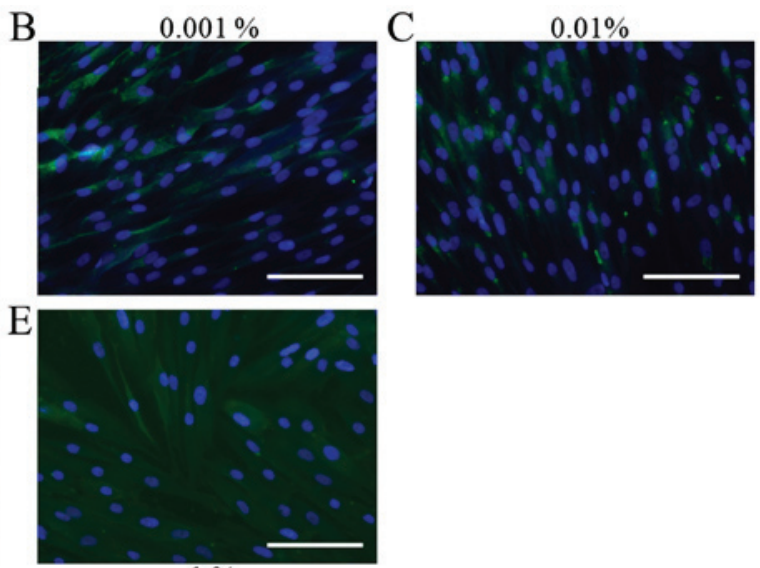

$1 \%$

Figure 9. Immunofluorescence staining for collagen I after 7 days of incubation with BBT. (A) Control group and (B) 0.001, (C) 0.01 , (D) 0.1 and (E) $1 \%$ BBT groups (original magnification, x200; scale bar, $200 \mu \mathrm{m}$ ). BBT, Bambusa tulda methanolic extract.

that a gradual reduction of collagen I expression occurred when higher doses of BBT were applied (Fig. 8). Similar trends for collagen I expression were observed in the presence of BBT on day 7 (Fig. 9).

\section{Discussion}

The present study investigated the effects of various concentrations of BBT on the morphology and cellular 
proliferation of stem cells derived from human gingival tissues. It was clearly demonstrated that the short-term application of Bambusa tulda enhanced the proliferation of mesenchymal stem cells with enhanced collagen I expression. Certain herbal extracts, which have long been used in traditional Asian medicine, are used as sources of novel therapeutics (7). These extracts may be considered prevalidated for effectiveness and are expected have fewer safety issues than chemically synthesized drugs $(7,8)$. In previous studies, various herbal extracts have been applied to mesenchymal stem cells for the enhancement of cell proliferation (9). Extracts of another herb, Polygala tenuifolia, promoted the proliferation of neural stem cells (10). Similarly, Ginkgo biloba herbal extract has been demonstrated to promote osteogenic differentiation of human bone marrow mesenchymal stem cells (11). Promotion of the neuronal differentiation of bone marrow stem cells was achieved by application of Salvia miltiorrhiza extract (12). In the present study, application of BBT enhanced the cell proliferation by up to $50 \%$ depending on the concentration and incubation time. With this regard, BBT may be applied to overcome the limited number of available cells or improve the survival of implanted stem cells. Herbal extracts may be combined with growth factors for synergistic effects (13).

There has been a great interest in using stem cells in cell therapy due to their promising characteristics that are beneficial for tissue regeneration and treatment of diseases (7). Stem cells have a self-renewal capacity and pluripotency with the ability to differentiate into various cell types, including bone, adipose tissue and cartilage $(14,15)$. Stem cells may be obtained from various sources, including the intraoral area $(16,17)$. Dental pulp and periodontal ligaments are considered preferred sources; however, due to the limited amount of tissue, an additional procedure of tooth extraction is required $(6,18)$. Gingiva may be a more favorable source of stem cells (19). Previous studies by our group indicated that gingiva-derived stem cells possessed colony-forming abilities, plastic adherence and a multilineage differentiation potency with the capacity to undergo osteogensis, adipogenesis and chondrogenesis, and expressed stem cell markers, including CD44, CD73, CD90 and CD105 (6,20). In addition, harvesting stem cells from gingiva may be easier than from bone marrow of the maxilla and mandible due to the lesser invasiveness, pain and paresthesia (21-23).

Various methods have been applied for the extraction of herbs (24). Cold pressing and expeller pressing use a heat-controlled environment, with a higher temperature being applied for expeller pressing (25). Various solvents, including ethanol, methanol, butanol, hexane, methylene chloride, ethyl acetate and water may be used for solvent extraction $(7,24,26,27)$. A novel method of microwave-assisted extraction was also developed for the extraction of Bambusa bambos (28). Different solubility and boiling points are noted between different types of solvents $(24,29)$. In a previous study, the dried powdered leaves were extracted with a hydroalcoholic mixture (30). It should be noted that different effects may be achieved depending on the type of solvent and the concentration (24).

Based on these findings, it was concluded that BBT produced beneficial effects on the proliferation of mesenchymal stem cells with enhanced collagen I expression at early time points.

\section{Acknowledgements}

This study was funded by the Ministry of Science, Information and Communication Technology (ICT) and Future Planning, Republic of Korea government [National Research Foundation of Korea (NRF) grant no. NRF-2016K1A1A8A01939075], the Catholic Institute of Cell Therapy (Seoul, Korea) and the Basic Science Research Program through the NRF funded by the Ministry of Science, ICT and Future Planning (grant no. NRF-2017R1A1A1A05001307).

\section{References}

1. Saxena S: In vitro propagation of the bamboo (Bambusa tulda Roxb.) through shoot proliferation. Plant Cell Rep 9: 431-434, 1990.

2. Sahariah B, Sinha I, Sharma P, Goswami L, Bhattacharyya P, Gogoi N and Bhattacharyya SS: Efficacy of bioconversion of paper mill bamboo sludge and lime waste by composting and vermiconversion technologies. Chemosphere 109: 77-83, 2014.

3. Larpkern P, Moe SR and Totland $\varnothing$ : Bamboo dominance reduces tree regeneration in a disturbed tropical forest. Oecologia 165: 161-168, 2011.

4. Waikhom SD and Louis B: An effective protocol for micropropagation of edible bamboo species (Bambusa tulda and Melocanna baccifera) through nodal culture. ScientificWorldJournal 2014: 345794, 2014

5. Bhattacharya S, Das M, Bar R and Pal A: Morphological and molecular characterization of Bambusa tulda with a note on flowering. Ann Bot 98: 529-535, 2006.

6. Jin SH, Lee JE, Yun JH, Kim I, Ko Y and Park JB: Isolation and characterization of human mesenchymal stem cells from gingival connective tissue. J Periodontal Res 50: 461-467, 2015.

7. Jeong SH, Lee JE, Jin SH, Ko Y and Park JB: Effects of Asiasari radix on the morphology and viability of mesenchymal stem cells derived from the gingiva. Mol Med Rep 10: 3315-3319, 2014.

8. Oh SM, Kim J, Lee J, Yi JM, Oh DS, Bang OS and Kim NS: Anticancer potential of an ethanol extract of Asiasari radix against HCT-116 human colon cancer cells in vitro. Oncol Lett 5: 305-310, 2013.

9. Cai B, Zhang AG, Zhang X, Ge WJ, Dai GD, Tan XL, Roodrajeetsing G and Cai JP: Promoting effects on proliferation and chondrogenic differentiation of bone marrow-derived mesenchymal stem cells by four 'Kidney-Tonifying' traditional Chinese herbs. Biomed Res Int 2015: 792161, 2015.

10. Park HJ, Lee K, Heo H, Lee M, Kim JW, Whang WW, Kwon YK and Kwon H: Effects of Polygala tenuifolia root extract on proliferation of neural stem cells in the hippocampal CA1 region. Phytother Res 22: 1324-1329, 2008.

11. Gu Q, Chen C, Zhang Z, Wu Z, Fan X, Zhang Z, Di W and Shi L: Ginkgo biloba extract promotes osteogenic differentiation of human bone marrow mesenchymal stem cells in a pathway involving Wnt/ $\beta$-catenin signaling. Pharmacol Res 97: 70-78, 2015.

12. Zhang N, Kang T, Xia Y, Wen Q, Zhang X, Li H, Hu Y, Hao H, Zhao D, Sun D, et al: Effects of salvianolic acid B on survival, self-renewal and neuronal differentiation of bone marrow derived neural stem cells. Eur J Pharmacol 697: 32-39, 2012.

13. Park JB: Combination of simvastatin and bone morphogenetic protein-2 enhances the differentiation of osteoblasts by regulating the expression of phospho-Smad1/5/8. Exp Ther Med 4: 303-306, 2012.

14. Ji M, Bai C, Li L, Fan Y, Ma C, Li X and Guan W: Biological characterization of sheep kidney-derived mesenchymal stem cells. Exp Ther Med 12: 3963-3971, 2016.

15. Ha DH, Yong CS, Kim JO, Jeong JH and Park JB: Effects of tacrolimus on morphology, proliferation and differentiation of mesenchymal stem cells derived from gingiva tissue. Mol Med Rep 14: 69-76, 2016.

16. Ballini A, De Frenza G, Cantore S, Papa F, Grano M, Mastrangelo F, Tetè $S$ and Grassi FR: In vitro stem cell cultures from human dental pulp and periodontal ligament: New prospects in dentistry. Int J Immunopathol Pharmacol 20: 9-16, 2007. 
17. Nagatomo K, Komaki M, Sekiya I, Ballini A, De Frenza G, Cantore S, Papa F, Grano M, Mastrangelo F, Tetè $S$ and Grassi FR: Stem cell properties of human periodontal ligament cells. J Periodontal Res 41: 303-310, 2006.

18. Park JB, Lee G, Yun BG, Kim CH and Ko Y: Comparative effects of chlorhexidine and essential oils containing mouth rinse on stem cells cultured on a titanium surface. Mol Med Rep 9: 1249-1253, 2014.

19. Zhang Q, Shi S, Liu Y, Uyanne J, Shi Y and Le AD: Mesenchymal stem cells derived from human gingiva are capable of immunomodulatory functions and ameliorate inflammation-related tissue destruction in experimental colitis. J Immunol 183: 7787-7798, 2009.

20. Jin SH, Kweon H, Park JB and Kim CH: The effects of tetracycline-loaded silk fibroin membrane on proliferation and osteogenic potential of mesenchymal stem cells. J Surg Res 192: e1-e9, 2014.

21. Park JB, Kim YS, Lee G, Yun BG and Kim CH: The effect of surface treatment of titanium with sand-blasting/acid-etching or hydroxyapaptite-coating and application of bone morphogenetic protein-2 on attachment, proliferation and differentiation of stem cells derived from buccal fat pad. Tissue Eng Regen Med 10 115-121, 2013.

22. Fournier BP, Larjava $H$ and Häkkinen L: Gingiva as a source of stem cells with therapeutic potential. Stem Cells Dev 22: 3157-3177, 2013.

23. Yang H, Gao LN, An Y, Hu CH, Jin F, Zhou J, Jin $Y$ and Chen FM: Comparison of mesenchymal stem cells derived from gingival tissue and periodontal ligament in different incubation conditions. Biomaterials 34: 7033-7047, 2013.
24. Wang MH, Jeong SH, Guo H and Park JB: Anti-inflammatory and cytotoxic effects of methanol, ethanol, and water extracts of Angelicae Dahuricae Radix. J Oral Sci 58: 125-131, 2016.

25. Kim SY, An SY, Lee JS and Heo JS: Zanthoxylum schinifolium enhances the osteogenic potential of periodontal ligament stem cells. In Vitro Cell Dev Biol Anim 51: 165-173, 2015.

26. Jeong SH, Kim BB, Lee JE, Ko Y and Park JB: Evaluation of the effects of Angelicae dahuricae radix on the morphology and viability of mesenchymal stem cells. Mol Med Rep 12: 1556-1560, 2015 .

27. Jeong SH, Lee JE, Kim BB, Ko Y and Park JB: Evaluation of the effects of Cimicifugae Rhizoma on the morphology and viability of mesenchymal stem cells. Exp Ther Med 10: 629-634, 2015.

28. Soumya V, Muzib YI and Venkatesh P: A novel method of extraction of bamboo seed oil (Bambusa bambos Druce) and its promising effect on metabolic symptoms of experimentally induced polycystic ovarian disease. Indian J Pharmacol 48: 162-167, 2016.

29. Mukudai Y, Zhang M, Shiogama S, Kondo S, Ito C, Motohashi H, Kato K, Fujii M, Shintani S, Shigemori H, et al: Methanol and butanol extracts of Paeonia lutea leaves repress metastasis of squamous cell carcinoma. Evid Based Complement Alternat Med 2016: 6087213, 2016.

30. Jawaid T, Awasthi A and Kamal M: Estrogenic activity of a hydro-alcoholic extract of Bambusa arundinaceae leaves on female wistar rats. J Adv Pharm Technol Res 6: 19-24, 2015. 